\title{
A comparative study on the effect of calcitriol and cinacalcet on hyperparathyroidism in hemodialysis patients; a double-blinded randomized clinical trial
}

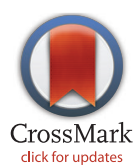

\author{
Saeed Mardani ${ }^{*}{ }^{\circledR}$, Faranak Sadat Filsouf ${ }^{(}$ \\ Department of Nephrology, Cancer Research Center, Shahrekord University of Medical Sciences, Shahrekord, Iran
}

\section{A R T I C L E I N F O}

Article Type:

Original

\section{Article History:}

Received: 10 May 2021

Accepted: 19 July 2021

Published online: 27 August 2021

\section{Keywords:}

Chronic kidney disease

Cinacalcet

Calcitriol

End-stage renal disease

Hemodialysis

\begin{abstract}
A B S T R A C T
Introduction: Chronic kidney disease (CKD) has lots of complication like calcium and phosphate metabolism disorders, hyperparathyroidism, vitamin D deficiency and metabolic acidosis. Objectives: The aim of this study was to determine and compare the effect of calcitriol and cinacalcet on hyperparathyroidism in hemodialysis patients due to end-stage renal disease (ESRD). Patients and Methods: This study was a double-blinded randomized clinical trial, which was conducted on 60 hemodialysis patients in 2017-2018. The patients were randomly assigned to two groups of 30 patients, which one group was treated with cinacalcet and the other group was treated with calcitriol. During this study, phosphorus, calcium and iPTH were measured.

Results: The results showed that in the group treated with cinacalcet, the amount of calcium $[\mathrm{t}(22)=0.294, P>0.05]$ and the amount of phosphorus $[\mathrm{t}(22)=1.87, P>0.05]$ did not change significantly while iPTH values before and after the study had statistically significant difference $[\mathrm{t}(22)=4.37, P<0.05]$. In group treated with calcitriol, the calcium, phosphorus and iPTH values did not change significantly $(P>0.05)$. Calcium changes in the cinacalcet group compared to the calcitriol group [ $\mathrm{t}(47)=-1.14, P>0.05]$ and also, the amount of phosphorus changes $[\mathrm{t}(47)=-1.022$, $P>0.05]$ was not statistically significant. The iPTH changes were not statistically significant between the two groups however iPTH in the calcitriol group was higher than the cinacalcet group [t $(47)=-1.13, P>0.05]$.

Conclusion: In contrast to calcitriol, cinacalcet significantly reduced iPTH and did not significantly change calcium and phosphorus levels.

Trial Registration: The trial was registered by Iranian Registry of Clinical Trials (IRCT) (identifier: IRCT20190702044076N1; https://en.irct.ir/trial/40547, Ethical code\# IR.SKUMS.REC.1397.026).
\end{abstract}

Implication for health policy/practice/research/medical education:

In a double-blinded randomized clinical trial, which was conducted on 60 hemodialysis patients, we found, calcitriol in contrast to cinacalcet significantly reduced intact parathyroid hormone and did not significantly change calcium and phosphorus levels. Please cite this paper as: Mardani S, Filsouf F. A comparative study on the effect of calcitriol and cinacalcet on hyperparathyroidism in hemodialysis patients; a double-blinded randomized clinical trial. J Nephropharmacol. 2022;11(1):e12. DOI: 10.34172/npj.2021.12.

\section{Introduction}

Chronic kidney disease $(\mathrm{CKD})$ is a degenerative and sclerotic disease that increases the filtration and hypertrophy of the remaining nephrons following damage to a number of nephrons (1). The prevalence of CKD is progressively increasing throughout the world and has grown substantially (2). The most common cause of CKD in 2015 was diabetes mellitus, followed by high hypertension, and glomerulonephritis (3). The complications of CKD are very widespread, like calcium and phosphate metabolism disorders, hyperparathyroidism, vitamin D deficiency, cardiovascular diseases, anemia, metabolic acidosis, and hypertension (4).

The term "CKD" refers to all five stages of kidney damage, from very mild damage in stage one to complete kidney failure in stage five (2). The findings of previous studies have shown that the combination of classical treatment and the cinacalcet treatment may further reduce parathyroid hormone $(\mathrm{PTH})$ in patients with $\mathrm{CKD}$ (5). Other studies have also shown that after 12-week cinacalcet treatment, the levels of PTH and fibroblast growth factor 23 (FGF23) are significantly decreased. 
These studies showed that cinacalcet reduces the serum FGF23 level in hemodialysis patients with secondary hyperparathyroidism independently of the active form of vitamin $\mathrm{D}(6)$.

\section{Objectives}

Considering the fact that CKD affects the entire body in many ways, it is vital to prevent the progression of renal degeneration and reduce its complications. The aim of the present study was to select the preferred therapeutic approach in terms of efficacy.

\section{Patients and Methods}

\section{Study design}

This study was conducted as a double-blinded randomized clinical trial in Hajar hospital in Shahrekord, Iran in 2017-2018. In this study, 60 hemodialysis patients were evaluated based on inclusion and exclusion criteria. Their clinical history and data were collected based on medical history. To enroll the patients in the study, the elevated PTH level was taken into account. Patients with PTH levels $>300 \mathrm{pg} / \mathrm{mL}$ were included in the study.

The aim of the present study was to reduce this level to below $300 \mathrm{pg} / \mathrm{mL}$ or decrease the initial value of this hormone by $30 \%$. The patients were divided into two groups through permuted block randomization and treated a group with calcitriol and the other with cinacalcet (Figure 1).

Cinacalcet treatment was started $(30 \mathrm{mg} / \mathrm{kg} / \mathrm{d})$ in the first group, consisted of 30 patients that had calcium level above $5.5 \mathrm{mg} / \mathrm{dL}$. The ultimate goal in this group was to achieve intact parathyroid hormone (iPTH) levels between 150 and $300 \mathrm{pg} / \mathrm{mL}$.

The second group $(n=30)$ was treated using calcitriol three times a week used as $0.250 \mu \mathrm{g}$. The patients of the calcitriol group had calcium $<10 \mathrm{mg} / \mathrm{dL}$ and phosphorus $>5.5 \mathrm{mg} / \mathrm{dL}$. In the case of iPTH levels between 300 and $600 \mathrm{pg} / \mathrm{mL}$, this group of patients received $0.5-1.5 \mathrm{pg} / \mathrm{mL}$ equivalent to 2-4 tablets three times a week. If iPTH levels were between $600 \mathrm{pg} / \mathrm{mL}$ and $1200 \mathrm{pg} / \mathrm{mL}$, they received 1.5-3 $\mu$ g equivalents to 4-8 tablets three times a week. The purpose of the treatment was similar to that of the first group. Then, the serum levels of calcium, phosphorus, and iPTH were measured in patients after 8 weeks of starting the study, and imported to the checklist. The patients and data analyzer were not aware of the allocated groups. Codes A and B were assigned to the names of groups for analzsing by data analyzer.

\section{Statistical analysis}

The data were analyzed using STATA version 11. For descriptive results, mean and standard deviation were presented. To investigate the predetermined outcomes, independent $t$ test, paired $t$ test and chi-square were applied. $P$ value less than 0.05 was considered significant.

\section{Results}

The present study was carried out on 60 patients with endstage renal disease (ESRD) who were undergoing dialysis and in the case of clinical evidence of heart failure or any

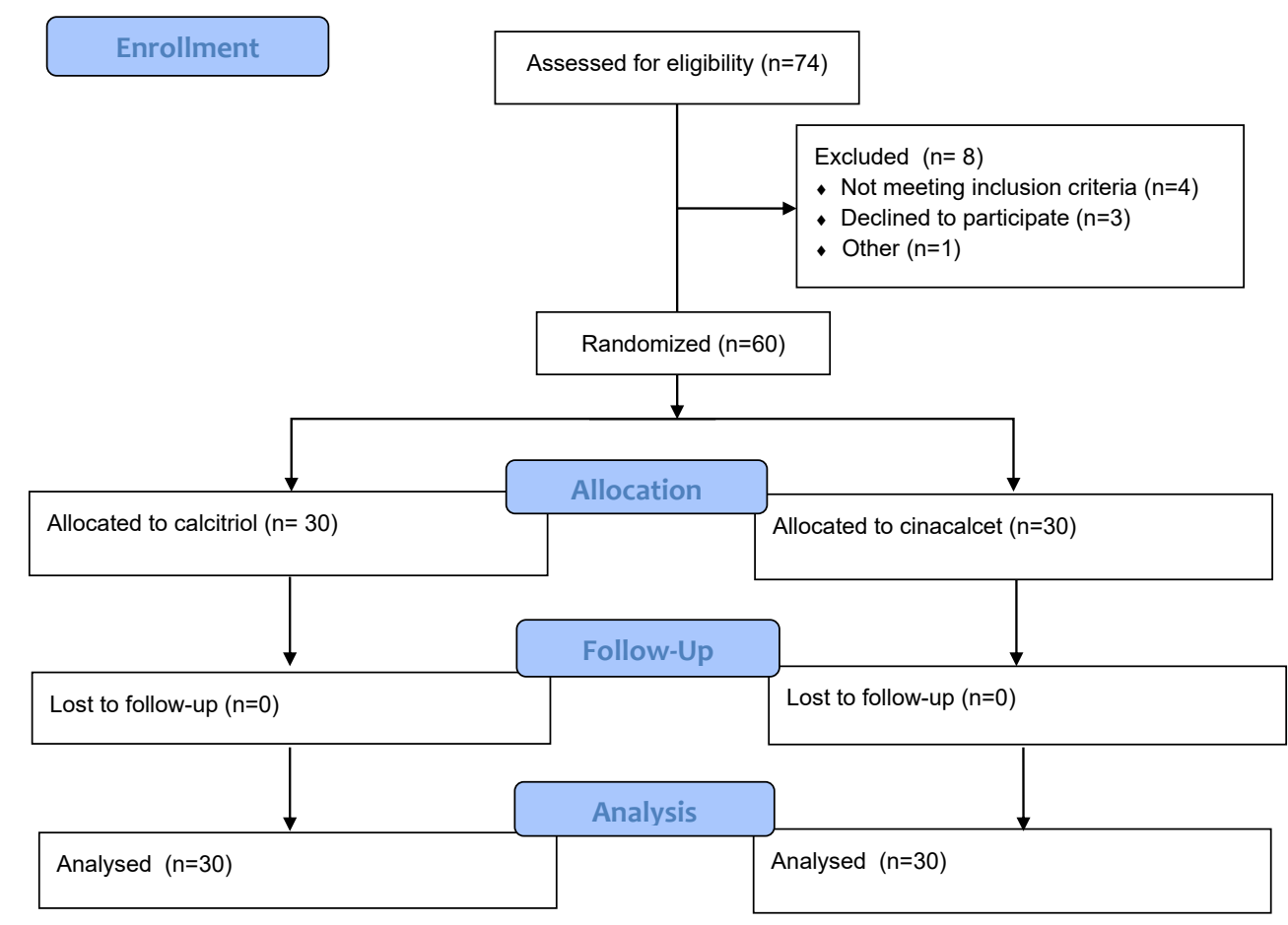

Figure 1. Flow chart showing the flow of patients through the trial (CONSORT). 
malignancy, the patients were excluded. Sixty patients were randomly divided into two groups (30 patients per group). The serum levels of calcium, phosphorus, and iPTH were measured in these patients. Table 1 shows the comparison of calcium, phosphorus, and iPTH levels in each group before and after treatment. In the cinacalcet group, the level of phosphorus and calcium did not change significantly $(P>0.05)$; however there was a significant difference between the two groups regarding pre- and post-intervention PTH levels $(P<0.05)$. Accordingly, in the calcitriol group, the calcium, phosphorus and iPTH values did not change significantly $(P>0.05)$.

According to Table 2, no statistically significant difference between the two groups regarding calcium and phosphorus changes was detected $(P>0.05)$. There was no statistically significant difference between the two groups regarding iPTH changes. The PTH was lower in the cinacalcet group than the calcitriol group that received vitamin $\mathrm{D}(P<0.05)$.

The results showed that out of 49 patients with ESRD, 23 patients $(46.9 \%)$ were in the cinacalcet group and 26 patients $(53.1 \%)$ were in the calcitriol group. The mean post and pre-treatment calcium level in the total subjects was $8.59 \pm 1.57 \mathrm{mg} / \mathrm{dL}$ and $8.4 \pm 0.8 \mathrm{mg} / \mathrm{dL}$, respectively. Regarding the phosphorus level in the total subjects, the mean post and pre-treatment levels were $5.27 \pm 1.26 \mathrm{mg} /$ $\mathrm{dL}$ and $5.8 \pm 1.9 \mathrm{mg} / \mathrm{dL}$, respectively. Finally, the mean post and pre-treatment of iPTH levels in all patients were $691.16 \pm 38.15 \mathrm{pg} / \mathrm{mL}$ and $943.86 \pm 621.65 \mathrm{pg} / \mathrm{mL}$, respectively (Table 3 ). Table 4 shows descriptive indicators of calcium, phosphorous and $\mathrm{PTH}$ in the cinacalcet and calcitriol groups

\section{Discussion}

In this study, 60 chronic kidney patients who had ESRD undergoing hemodialysis were included and in case of clinical evidence of heart failure or any malignancy, the patients were excluded. Our results show that cinacalcet effectively lowers parathyroid hormone levels in the patients with secondary hyperparathyroidism treated with hemodialysis, leading to a slight increase in calcium that was not statistically significant and a decrease in serum phosphorus. Our patients with serum iPTH levels above $300 \mathrm{pg} / \mathrm{mL}$ and calcium above $8.5 \mathrm{mg} / \mathrm{dL}$ were included in the study, and the aim of our study was to reduce this level to below $300 \mathrm{pg} / \mathrm{mL}$ or a $30 \%$ reduction in the initial amount of this hormone.

In this study, iPTH levels decreased after treatment with cinacalcet, and this response was constant in different patients. According to the obtained results and

Table 1. Comparison of serum levels of phosphorus, calcium and iPTH before and after treatment

\begin{tabular}{|c|c|c|c|c|c|}
\hline Variable & & $\begin{array}{c}\text { Before intervention } \\
\text { Mean } \pm \text { SD }\end{array}$ & $\begin{array}{l}\text { After intervention } \\
\text { Mean } \pm S D\end{array}$ & Correlation ( $r$ ) & $P$ value \\
\hline \multirow{3}{*}{ Cinacalcet group } & Calcium (mg/dL) & $8.68 \pm 0.682$ & $8.57 \pm 1.77$ & 0.092 & 0.772 \\
\hline & Phosphorus (mg/dL) & $6.17 \pm 2.17$ & $5.33 \pm 1.16$ & 0.282 & 0.075 \\
\hline & iPTH (pg/mL) & $1099.6 \pm 533.48$ & $739.51 \pm 492.99$ & 0.707 & 0.001 \\
\hline \multirow{3}{*}{ Calcitriol group } & Calcium (mg/dL) & $8.15 \pm 0.84$ & $8.61 \pm 1.40$ & -0.047 & 0.170 \\
\hline & Phosphorus (mg/dL) & $5.48 \pm 1.59$ & $5.21 \pm 1.26$ & 0.204 & 0.471 \\
\hline & iPTH (pg/mL) & $806.09 \pm 670.43$ & $648.40 \pm 246.98$ & -0.258 & 0.308 \\
\hline
\end{tabular}

Table 2. Comparison of serum levels of phosphorus, calcium and PTH between groups

\begin{tabular}{lccc}
\hline Group & $\begin{array}{c}\text { Calcium changes } \\
\text { Mean } \pm \text { SD }\end{array}$ & $\begin{array}{c}\text { Phosphorus group } \\
\text { Mean } \pm \text { SD }\end{array}$ & $\begin{array}{c}\text { iPTH group } \\
\text { Mean } \pm \text { SD }\end{array}$ \\
\hline Cinacalcet group & $-0.113 \pm 1.844$ & $-0.843 \pm 2.16$ & $-360.09 \pm 394.41$ \\
Calcitriol group & $0.461 \pm 1.660$ & $-0.26 \pm 1.82$ & $-157.692 \pm 771.91$ \\
$P$ value & 0.258 & 0.312 & 0.262 \\
\hline
\end{tabular}

Table 3. Descriptive indicators of the studied variables in the patients before and after treatment

\begin{tabular}{|c|c|c|c|c|c|}
\hline Variable & & Mean & SD & Min & Max \\
\hline \multirow{2}{*}{ Calcium (mg/dL) } & Before intervention & 8.59 & 1.57 & 5.7 & 11.9 \\
\hline & After intervention & 8.4 & 0.80 & 5.7 & 9.9 \\
\hline \multirow{2}{*}{ Phosphorous (mg/dL) } & Before intervention & 5.27 & 1.26 & 1.2 & 8 \\
\hline & After intervention & 5.8 & 1.90 & 2.7 & 10.5 \\
\hline \multirow{2}{*}{ iPTH (pg/mL) } & Before intervention & 691.16 & 381.15 & 88 & 1996 \\
\hline & After intervention & 943.86 & 621.65 & 300 & 3807 \\
\hline
\end{tabular}


Table 4. Descriptive indicators of the studied variables in the participants by groups

\begin{tabular}{|c|c|c|c|c|c|c|}
\hline Variable & & & Mean & SD & Min & Max \\
\hline \multirow{6}{*}{ Cinacalcet group } & \multirow{2}{*}{ Calcium (mg/dL) } & Before intervention & 8.57 & 1.77 & 5.7 & 11 \\
\hline & & After intervention & 8.68 & 0.68 & 8.6 & 9.8 \\
\hline & \multirow{2}{*}{ Phosphorous (mg/dL) } & Before intervention & 5.33 & 1.16 & 3.8 & 8 \\
\hline & & After intervention & 6.17 & 2.17 & 2.7 & 10.5 \\
\hline & \multirow{2}{*}{ ¡PTH (pg/mL) } & Before intervention & 739.51 & 492.99 & 88 & 1996 \\
\hline & & After intervention & 1099.60 & 533.48 & 300 & 2523 \\
\hline \multirow{6}{*}{ Calcitriol group } & \multirow{2}{*}{ Calcium (mg/dL) } & Before intervention & 11.9 & 6.4 & 1.40 & 8.61 \\
\hline & & After intervention & 9.9 & 5.7 & 0.84 & 8.15 \\
\hline & \multirow{2}{*}{ Phosphorous (mg/dL) } & Before intervention & 5.21 & 1.26 & 2.7 & 7.6 \\
\hline & & After intervention & 5.48 & 1.59 & 3.6 & 10.5 \\
\hline & \multirow{2}{*}{ iPTH (pg/mL) } & Before intervention & 648.4 & 246.98 & 182 & 1047 \\
\hline & & After intervention & 806.09 & 670.43 & 300 & 3807 \\
\hline
\end{tabular}

the conducted studies, some points can be made. In the study by Dou et al, patients were divided into two groups, in the first group who received vitamin D; they reported significant differences between iPTH and calcium levels (7). In our second group, after receiving a vitamin $\mathrm{D}$, calcium levels increased from $8.15 \mathrm{mg} / \mathrm{dL}$ to $8.61 \mathrm{mg} /$ $\mathrm{dL}$ and $\mathrm{iPTH}$ decreased from $806.09 \pm 670.434 \mathrm{pg} / \mathrm{mL}$ to $648.4 \pm 246.98 \mathrm{pg} / \mathrm{mL}$. However, this difference was not statistically significant. Additionally, changes in phosphorus levels were not reported in the study, since we observed a decrease from $5.48 \mathrm{mg} / \mathrm{dL}$ to $5.21 \mathrm{mg} / \mathrm{dL}$ in our study.

The study by Wetmore et al on 312 patients; showed, the level of iPTH decreased after administration of cinacalcet and vitamin $\mathrm{D}$. They were also found to have a more common decrease in calcium (hypocalcemia) in the cinacalcet group. In our study, we also encountered some forms of hypocalcemia in the cinacalcet group (8). In our study, the mean calcium levels in the cinacalcet and calcitriol group were $8.57 \mathrm{mg} / \mathrm{dL}$ and $8.61 \mathrm{mg} / \mathrm{dL}$, respectively, which did not have any kind of hypercalcemia. In the case of phosphorus, hyperphosphatemia was not observed in all study groups with a mean of $5.33 \mathrm{mg} / \mathrm{dL}$ and $5.21 \mathrm{mg} / \mathrm{dL}$ respectively after treatment. Likewise, to the study by Drüeke et al, based on treatment with cinacalcet and vitamin $\mathrm{D}$, a greater decrease was observed in iPTH of the cinacalcet group (9), which was consistent with our results.

\section{Conclusion}

In contrast to calcitriol, cinacalcet significantly reduced PTH and did not significantly change calcium and phosphorus levels.

\section{Limitations of the study}

The interventional nature of the research does not allow recruiting more patients. Then, small sample size was the main limitation in this study.

\section{Acknowledgments}

The authors would like to thank the vice chancellor for research of Shahrekord University of Medical Sciences.

\section{Authors' contribution}

All authors participated in preparing the final draft of the manuscript, revised the manuscript and critically evaluated the intellectual contents. All authors have read and approved the content of the manuscript and confirmed the accuracy or integrity of any part of the work. FF and SM were the principal investigators of the study. FF prepared the primary draft. SM conducted finalized the paper. All authors read and signed the final manuscript.

\section{Conflicts of interest}

The authors declare that there is no conflict of interest.

\section{Ethical issues}

The research followed the tenets of the Declaration of Helsinki. This study was approved by ethic committee of Shahrekord University of Medical Sciences (Ethical code\#IR.SKUMS.REC.1397.026). Moreover, the study protocol was registered by the Iranian Registry of Clinical Trials (identifier: IRCT20190702044076N1; https:// en.irct.ir/trial/40547). Accordingly, informed consent was obtained from all the patients. Moreover, ethical issues (including plagiarism, data fabrication, double publication) have been completely observed by the authors. This study was extracted from M.D., thesis of Faranak Sadat Filsouf at this university (Thesis \#2700).

\section{Funding/Support}

This study was funded by Shahrekord University of Medical Sciences.

\section{References}

1. Datta S, Abraham G, Mathew M, Somasundaram H, Muralidharan TR, Moorthy A, et al. Correlation of anemia, secondary hyperparathyroidism with left ventricular 
hypertrophy in chronic kidney disease patients. J Assoc Physicians India. 2006;54:699-703.

2. Liao MT, Sung CC, Hung KC, Wu CC, Lo L, Lu KC. Insulin resistance in patients with chronic kidney disease. J Biomed Biotechnol. 2012;2012:691369. doi: 10.1155/2012/691369.

3. Vos T, Allen C, Arora M, Barber RM, Bhutta ZA, Brown A, et al. Global, regional, and national incidence, prevalence, and years lived with disability for 310 diseases and injuries, 1990-2015: a systematic analysis for the Global Burden of Disease Study 2015. Lancet. 2016;388:1545-602. doi: 10.1016/s0140-6736(16)31678-6.

4. Wen CP, Cheng TY, Tsai MK, Chang YC, Chan HT, Tsai SP, et al. All-cause mortality attributable to chronic kidney disease: a prospective cohort study based on 462293 adults in Taiwan. Lancet. 2008;371:2173-82. doi: 10.1016/s01406736(08)60952-6.

5. Saliba W, El-Haddad B. Secondary hyperparathyroidism: pathophysiology and treatment. J Am Board Fam Med. 2009;22:574-81. doi: 10.3122/jabfm.2009.05.090026.
6. Koizumi M, Komaba H, Nakanishi S, Fujimori A, Fukagawa M. Cinacalcet treatment and serum FGF23 levels in haemodialysis patients with secondary hyperparathyroidism. Nephrol Dial Transplant. 2012;27:784-90. doi: 10.1093/ndt/gfr384.

7. Dou D, Yang B, Gan H, Xie D, Lei H, Ye N. Vitamin D supplementation for the improvement of vascular function in patients with chronic kidney disease: a metaanalysis of randomized controlled trials. Int Urol Nephrol. 2019;51:851-8. doi: 10.1007/s11255-019-02088-3.

8. Wetmore JB, Gurevich K, Sprague S, Da Roza G, Buerkert $\mathrm{J}$, Reiner $\mathrm{M}$, et al. A randomized trial of cinacalcet versus vitamin $\mathrm{D}$ analogs as monotherapy in secondary hyperparathyroidism (PARADIGM). Clin J Am Soc Nephrol. 2015;10:1031-40. doi: 10.2215/cjn.07050714.

9. Drüeke TB, Ritz E. Treatment of secondary hyperparathyroidism in CKD patients with cinacalcet and/or vitamin D derivatives. Clin J Am Soc Nephrol. 2009;4:234-41. doi: 10.2215/cjn.04520908.

Copyright $\odot 2022$ The Author(s); Published by Society of Diabetic Nephropathy Prevention. This is an open-access article distributed under the terms of the Creative Commons Attribution License (http://creativecommons.org/licenses/by/4.0), which permits unrestricted use, distribution, and reproduction in any medium, provided the original work is properly cited. 